TITLE:

\title{
The Tai Chimpanzee Project in Cote d'Ivoire, West Africa
}

$\operatorname{AUTHOR}(S)$ :

Boesch-Achermann, Hedwige; Boesch, Christophe

\section{CITATION:}

Boesch-Achermann, Hedwige ... [et al]. The Tai Chimpanzee Project in Cote d'Ivoire, West Africa. Pan Africa News 1994, 1(1): 5-7

\section{ISSUE DATE:}

1994

URL:

http://hdl.handle.net/2433/143537

RIGHT:

Copyright (C) Pan Africa News. 


\section{The Taï Chimpanzee Project in Cote d'Ivoire, West Africa}

The pioneering work of Jane Goodall and Toshisada Nishida was done on chimpanzees living in East Africa within a mosaic savanna woodland, a relatively dry habitat. The majority of wild chimpanzees, however, live in the heart of the tropical rainforest belt in Central and West Africa. The Taî chimpanzee project and the chimpanzee research project in Bossou, Guinea were the first long-term studies undertaken on rainforest chimpanzees.

\section{The current situation at Tai}

The cruel shadows of civil war are spreading from Liberia into the peaceful country of Cote d'Ivoire. Day and night the stream of refugees flows into Tai village, which is also the logistic base for the scientists and home of the field assistants working in the chimpanzee project. Since the arrival of refugees began three years ago, the population along the frontier between the two countries has doubled. Mothers have lost babies during their fearful flight through abandoned countryside and dark forest, before they could reach their saving destination across the border. Many never arrived. The Ivorians responded with overwhelming generosity to the 'need for care of the refugees, and could serve as a model for many wealthy European countries. Most of our local assistants have accepted from 10 to 20 persons into their families, providing them for a start with food and shelter. Quite understandably, the majority of refugees would like to start ane $w$ in their host country; in the hope of someday leading àgain a decent and joyful life. Obviously, the situation adds to the strain on the already heavily burdened Ivorian government, which has been facing economic problems for several years now. Disastrous international prices for coffee and cocoa over the last 5 years have destroyed the years-long work of many farmers.

With regard to conservation, the Ivorian government had already taken steps in 1965 to protect some of the country's forests from logging and burning for plantation and farmland by creating national parks and protected forests, and the laws to safeguard them. Hunting is forbidden by law throughout Ivory Coast. However, illegal logging and poaching have always been and still are the major threats to the parks, forests and wild animals.

The Taï National Park is the largest, and one of the oldest remnants of tropical forest in West Africa, dating from 18,000 years ago in the late Pleistocene. Thus, it is a refuge for forest fauna. The last big populations of chimpanzees and the last dwindling populations of forest elephants live there, along with other endemic species such as the pygmy hippo, two species of forest duiker and three species of monkey. Although the Taï NP has faced pressure from a growing population since its creation in 1976, the Ivorian authorities have succeeded in keeping most of the forest intact. The WWF and more recently technical assistance from Germany are helping the government ensure the long-term survival of the park.

\section{The Taï chimpanzee project}

We started the project in July 1979 after a preliminary 10 month study conducted in 1976 . The outstandingly generous attitude of the Ivorian government toward foreign scientists and the stable political situtation in Cote d'Ivoire enabled us to establish an efficient, long-term study on rainforest chimpanzees, which at the time were little known by the scientific community. The "Centre Suisse de Recherche Scientifique (CSRS) 
in Abidjan officially represents all Swiss scientists working in the country and acts as a liaison with the Ivorian government. Our study site was chosen to be on the western side of Taï National Park, about $20 \mathrm{~km}$ from Tai village and the Liberian border, and $8 \mathrm{~km}$ from the Station IET (Institut d'Ecologie Tropical) built in 1977 for a UNESCO-MAB project. Taï is a "SousPréfecture", which means that official representatives of the government are stationed there. The proximity to Tai with its daily bus connections to Abidjan, $600 \mathrm{~km}$ across the country, and an abundant weekly food market and various shops including a pharmacy, make the site ideal from a logistical point of view. The constant presence of the scientists and field staff at our study site as well as at the Station IET certainly increases the level of protection of this part of Taï NP. Many visitors, for example, comment on the striking abundance of arboreal monkeys in the region. This emphasizes the importance of the establishment of long-term study sites with both scientific and conservation aims.

\section{Methodology of the research}

After we decided on the project site, we chose to work alone so as to keep the disturbance as little as possible. For the same reason we did not cut transects but learned to orient ourselves in the forest with a compass, and by learning the forest structure, streams and vegetation types. The basic method was "being seen by the chimpanzees as often as possible and always in a peaceful, discreet attitude." It took about 5 years to see the first serious results, during which we documented the regular, gradual increases in the chimps' level of habituation. The Taï chimpanzees are still the only chimpanzee community fully habituated to human observers without the use of any artificial provisioning. We deliberately did not provision in 1979 because our main theme, the study of nut-cracking behavior, is a feeding behavior and provisioning might have interfered with it. Habituation to us means the ability to observe wild chimpanzees at perfect visibility range without interrupting their normal behavior, and to be able to keep them within sight while following on foot at a distance of about $10 \mathrm{~m}$.

Six years after we began we decided to introduce the first local field assistant, Gregoire Nohon, and two graduate students from Switzerland, Martina Funk and Rainer Neumeier. Since then, 3 local field assistants have been trained to work permanently at our study site, and many expatriate students study the Taî chimpanzees with their invaluable help. In 1989, we began the habituation of a neighboring community of chimpanzees. This process is now in its fourth year and we are beginning to see some progress.

\section{The habituation process}

It took 20 months of continuous follows of the chimpanzees by the two of us before we noticed the first sign of progress, namely that some chimps would look at us for a short while before running away. The first two years we saw chimpanzees only about $1 \%$ of the time we spent looking for them. The third and fourth year some progress occurred as observation time increased to 5 and $15 \%$, respectively. Four years and 8000 field hours yielded $\mathbf{4 4 0}$ hours of actual observation, which is a good reflection of the difficult forest conditions. It was only in the fifth year that most males could be observed and one male, Le Chinois, could be followed in the forest. Generally, males proved to be less shy than females who resisted habituation much longer. After 15 years some females are still difficult to follow at a close distance for a whole day. From our experience we can conclude that chimpanzee habituation is dependent upon the number of positive contacts (the intruder not being perceived as dangerous) one succeeds in making with each individual. New immigrant females start to tolerate us now after 8 rapid visual contacts. Obviously, the indifference of the other, habituated chimpanzees helps enormously. Given a community of $\mathbf{4 0}$ nonhabituated individuals and using the optimistic rate of 8 positive sightings, the process of habituation would require at least two years. As chimpanzees rapidly identify human faces, the observers doing the habituation should be the same for the initial period. Certainly, the use of bushknives is to be totally banned during this time.

The task was difficult but we were privileged because the chimpanzees actively helped with their habituation! They use heavy tools to pound nuts, more or less frequently throughout the year, and this behavior was our main study topic for the first six years. The sound of nut cracking can be heard from a distance, which means that the tool-using animal can be located precisely before being approached, often allowing us to see before being seen. Whenever possible, individual physical details such as sex, the presence of infants, efficiency measures on nut cracking and details on tools were recorded before the chimpanzees 
noticed our presence. We wrote an article on sex differences in tool use from data obtained on nonhabituated chimpanzees, the sex of a chimpanzee being easily detectable when it leaves, even if it leaves in a hurry!

\section{Field staff and housing}

To keep the strain on constantly-followed chimpanzees as low as possible, we accept at most two scientists per year at the study site, and tend now to favour studies on a long-term basis, i.e. those that involve two years or more of data collection. This enables, in combination with the efforts of the three field assistants, almost complete day-to-day follows of the chimpanzees. Furthmore, we are able to function with this limited group size, even in the occasional absence of the person in charge of the site. The assistants from the nearby village of Ponan, Grégoire Nohon, Honora Kpazahi and Mathias Douosson, participate directly in the project. The first, simple camp built in 1979 is still usable and able to house 2 to 3 persons. The local assistants have a camp of similar size nearby, and there is another small camp situated within the territory of the neighboring chimpanzee group. Water is a constant problem, and sometimes has to be transported from the Station IET, a distance of 8 km. has antw Topics of study at Taï

Nut-cracking behavior. was the initial topic through the first years, and has been thoroughly studied and documented by the two of us (Boesch\&Boesch, 1981, 1983, 1984a, b, 1990). An archaeological approach to nut cracking, based on analysis of traces, was used in a study that involved Ch. Falquet and C. Steiner. Also, P. and N. Marchesi, B. Fruth and F. Joulian worked together on a project on tool tradition in Ivory Coast, thus giving insight into the techniques of nut cracking by chimpanzees in Cote d'Ivoire (Boesch et al., in press) and on possible subtle differences between populations. (The Marchesis also did a country-wide census of chimpanzees in Ivory Coast but were interrupted by the war during an attempt to do the same in Liberia (Marchesi et al., in press)).

Predator/prey interactions and the evolution of cooperation in wild chimpanzees. Hunting became the second main topic after tool use, is still under study by $\mathrm{Ch}$. Boesch, and has given rise to a comparative study with Gombe chimpanzees. The many, fascinating differences emerging between savanna and forest chimpanzees emphasizes the importance of continued study of these animals (Boesch\&Boesch, 1989; Boesch a, b, in press).
Comparative studies. A long-term mother/infant project which commenced in 1989 and has involved anumber of students (M.

Hoitink, P. Gagneux, P. Simpson, M. Behrens). A comparative study of locomotion in chimpanzees and bonobos was done by $D$. Doran. C. Steiner is presently studying female relations. A detailed study of the males will soon start, based on a preliminary year of data collection by $\mathrm{A}$. Kurt.

Population genetics. P. Gagneux began the

West African work on this topic. He and his wife Barbara are presently on their first hair sample collection trip. (ed. note: see Classifieds)

Intercommunity interactions. The habituation of the neighboring chimpanzee community began with the assistance of $G$. Radl, was continued by F. Donata and S. Pieren and the help of several field assistants (V. Yagnon and B. Zapaki at present). (ed. note: see Classifieds)

Predator/prey interactions in the tropical rainforest. A forest leopard project started by $D$. Jenny with assistance from G. Gah will hopefully lead to some answers regarding the high mortality rate chimpanzees suffer due to leopards. We are planning a further study on the crowned eagle $(e d$. note: see Classifieds) The chimpanzee, leopard and eagle prey upon monkeys; leopards also prey upon chimpanzees. To understand the hunting tactics of these three predators and the reaction of the prey (which has also been studied by R. Noë and his research group at the Taï Station IET) will help us gain insight into a prey/predator system in the tropical rainforest.

Hedwige Boesch-Achermann and Christophe Boesch, University of Basel 